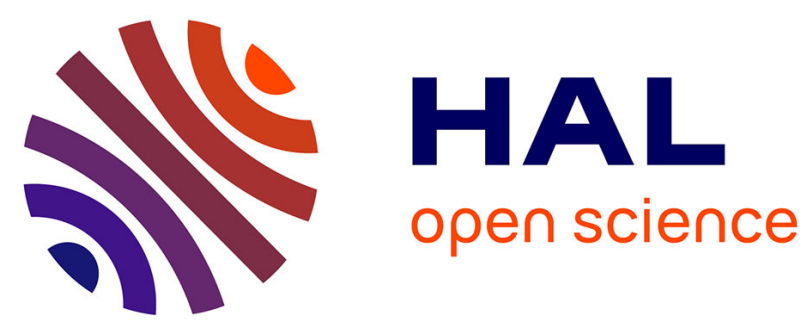

\title{
VEGF increases the fibrinolytic activity of endothelial cells within fibrin matrices: involvement of VEGFR-2, tissue type plasminogen activator and matrix metalloproteinases.
}

David Ratel, Samira Mihoubi, Edith Beaulieu, Yves Durocher, Georges-Etienne Rivard, Denis Gingras, Richard Béliveau

\section{To cite this version:}

David Ratel, Samira Mihoubi, Edith Beaulieu, Yves Durocher, Georges-Etienne Rivard, et al.. VEGF increases the fibrinolytic activity of endothelial cells within fibrin matrices: involvement of VEGFR-2, tissue type plasminogen activator and matrix metalloproteinases.. Thrombosis Research, 2007, 121 (2), pp.203-12. 10.1016/j.thromres.2007.03.024 . inserm-00383800

\section{HAL Id: inserm-00383800 https://www.hal.inserm.fr/inserm-00383800}

Submitted on 3 Jul 2009

HAL is a multi-disciplinary open access archive for the deposit and dissemination of scientific research documents, whether they are published or not. The documents may come from teaching and research institutions in France or abroad, or from public or private research centers.
L'archive ouverte pluridisciplinaire HAL, est destinée au dépôt et à la diffusion de documents scientifiques de niveau recherche, publiés ou non, émanant des établissements d'enseignement et de recherche français ou étrangers, des laboratoires publics ou privés. 


\section{VEGF increases the fibrinolytic activity of endothelial cells within fibrin matrices. Involvement of VEGFR-2, tissue type plasminogen activator and matrix metalloproteinases ${ }^{\pi}$}

David Ratel $^{1 a}$, Samira Mihoubi ${ }^{1}$, Edith Beaulieu ${ }^{1}$, Yves Durocher ${ }^{2}$, Georges-Etienne Rivard $^{3}$, Denis Gingras ${ }^{1 *}$, and Richard Béliveau ${ }^{1,3 *}$

${ }^{1}$ Laboratoire de Médecine Moléculaire Ste-Justine-UQAM, Centre de Cancérologie Charles-Bruneau, Hôpital Ste-Justine et Université du Québec à Montréal, 3175 Chemin Côte-Ste-Catherine, Montréal, Qc, Canada H3T 1C5, ${ }^{2}$ Animal Cell Technology Group, Biotechnology Research Institute, National Research Council Canada, 6100 Royalmount Avenue, Montréal, Québec, Canada, H4P2R2 and ${ }^{3}$ Service d'Hématologie-Oncologie, Hôpital Ste-Justine, Montréal, Québec, Canada H3T 1C5

*Corresponding authors: Laboratoire de médecine moléculaire, Centre de recherche de l'Hôpital Ste-Justine, 3175 Chemin Côte-Ste-Catherine, Montréal, QC, Canada H3T 1C5. Tel: (514) 345-2366; Fax: (514) 345-2359

E-mail: molmed@recherche-ste-justine.qc.ca

Key words: tissue type plasminogen activator, vascular endothelial growth factor, fibrin degradation, metalloproteases.

Abbreviations: MMP, matrix metalloproteinase, tPA, tissue-type plasminogen activator, PAGE, polyacrylamide gel electrophoresis; PAI-1, Plasminogen Activator Inhibitor Type-1. VEGF, vascular endothelial growth factor; uPA, urokinase-type plasminogen activator,

${ }^{a}$ Present address: INSERM U318, UJFG, CHU Michallon, 38043 Grenoble, France.

II This work was supported by a grant from the Canadian Institutes for Health Research to D.G. and R.B. 


\begin{abstract}
Proteolysis of fibrin matrices by endothelial cells plays essential roles in the migratory and morphogenic differentiation processes underlying angiogenesis. Using an in vitro fibrinolysis model consisting of human umbilical vein endothelial cells (HUVECs) embedded in a three dimensional fibrin matrix, we show that VEGF, an angiogenic cytokine that plays a crucial role in the onset of angiogenesis, is a potent activator of HUVEC-mediated fibrinolysis. This VEGF-dependent fibrin degradation was completely abrogated by inhibitors of either the plasminogen activator/plasmin or matrix metalloproteinases (MMP) proteolytic systems, suggesting the involvement of both classes of proteases in fibrin degradation. Accordingly, VEGF-induced fibrinolysis correlated with an increase in the expression of tPA and of some MMPs, such as MT2MMP and was completely blocked by a neutralizing antibody against tPA. Overall, these results indicate that efficient proteolysis of three dimensional fibrin matrices during VEGF-mediated angiogenesis involves a complex interplay between the MMP and plasmin-mediated proteolytic systems.
\end{abstract}




\section{INTRODUCTION}

Tumor angiogenesis is an extremely complex process in which tumor cells, either in response to hypoxia or through genetic modifications associated with malignancy, secrete a number of stimulatory cytokines, of which the vascular endothelial growth factor (VEGF) is the most often associated with the onset of angiogenesis [1]. The binding of VEGF to the VEGFR-1 (Flt-1) and VEGFR-2 (Flk-1) receptors at the endothelial cell (EC) surface triggers a number of intracellular signaling events that ultimately lead to increased proliferation, migration and survival of the EC [2]. In addition, VEGF is a potent inducer of vascular permeability, resulting in the extravasation of plasma fibrinogen in the extravascular space, which is then clotted to a cross-linked fibrin provisional matrix via the proteolytic action of thrombin [3]. This fibrin matrix appears to be essential for neovascularization, allowing migration of the activated EC towards the chemotactic stimulus as well as by acting as an essential substrate for the morphogenesis of EC into tubular structures [4]. Since new vessels are highly permeable, fibrin is continuously present into the tumor stroma and triggers the activation of the coagulation system [5]. The important role of fibrin deposition and degradation in neovessel formation thus highlights the crucial function of the hemostatic system in the regulation of angiogenesis and tumor growth $[6,7]$.

Fibrin matrices form three-dimensional scaffolds that provide cell-attachment sites and mechanical support for invading EC but also act as a barrier through which EC must

penetrate to facilitate the formation of new capillaries [8]. The proteolytic degradation of 
this fibrin matrix can be mediated by plasmin, a potent fibrinolytic enzyme which is activated from its zymogen plasminogen urokinase- and tissue-type plasminogen activators [9]. Several studies have shown that uPA-mediated plasmin generation plays important roles in cell migration, tissue remodelling, and in angiogenesis and tumor growth [10-12]. Although the role of tPA-mediated plasmin activation in angiogenesis is much less understood, the activity of t-PA correlates with a poor prognosis in several cancers $[13,14]$ and, at least in some cases, its overexpression promotes growth and angiogenesis in vitro and in vivo [15].

In spite of the importance of PA-mediated plasmin formation for fibrin degradation, mice lacking either uPA, tPA or plasminogen show no significant alteration in the neovascularization of fibrin-rich tissues [16]. It was subsequently shown that EC from these animals retain the ability to invade fibrin matrices due to the pericellular fibrinolysis mediated by membrane type MMPs $[17,18]$. Such an important role of membrane-anchored MMPs in fibrinolysis is also suggested by the ability of EC to undergo plasmin-independent tubulogenesis within fibrin gels, a property most likely related to an increased expression of MT1-, MT2- and MT3-MMP [19]. In the presence of plasminogen, however, both plasmin and MMP activities were required for efficient invasion of fibrin matrices [20]. These observations thus suggest the existence of a complex relationship between the PA/plasminogen and MMP proteolytic systems that may be modulated by the microenvironment surrounding the EC.

In order to study in more details the mechanisms involved in EC-mediated fibrin degradation, we used an in vitro fibrinolysis model consisting of human vascular endothelial cells embedded in a three dimensional fibrin matrix in the presence of 
plasminogen from the culture medium. This model probably more closely mimics the in vivo cellular microenvironment since in comparison with conventional cultures, cells in three dimensional cultures behave very differently in their responses to their biological and biophysical environnement [21], leading to distinct patterns of signal transduction and of gene expression [22].

Using this cell system, we observed that the angiogenic cytokine VEGF markedly increases the fibrinolytic activity of endothelial cells, this effect occurring through a VEGFR-2-dependent activation of both plasminogen activator and metalloprotease proteolytic systems. This VEGF-induced fibrinolysis by endothelial cells depends on the synthesis and activity of tPA and is correlated with the up-regulation of membraneassociated members of the MMP family, MT-MMPs. 


\section{MATERIALS AND METHODS}

\section{Materials}

Plasminogen-free human fibrinogen, recombinant human PAI-1 and human plasmin were obtained from Calbiochem (La Jolla, CA). ${ }^{125}$ I-labeled fibrinogen was from Amersham Biosciences (Baie d'Urfé, QC, Canada). Aprotinin was from Roche (Laval, Qc, Canada). Thrombin was obtained from Sigma Co. (St-Louis, MO). VEGF was produced and purified as recently described [23]. PDGF-BB, PlGF and HGF/SF were from R\&D Systems (Minneapolis, MN) while EGF was from BD Biosciences Discovery Labware (Bedfod, MA). Trizol reagent and the Superscript One-step RT-PCR kit were obtained from Invitrogen (Burlington, ON). Cycloheximide was from Sigma while TIMP-2 was purchased from Chemicon. The VEGFR-2 inhibitor PTK787/ZK222584 (PTK787) was kindly provided by Novartis AG (Basel, Switzerland). Monoclonal antibody against tissue plasminogen activator (tPA) was obtained from American Diagnostica (Stamford, CT). Purified nonimmune mouse $\operatorname{IgG}_{1} \mathrm{~s}$ (Sigma) were used as a control.

\section{Cell culture}

Primary human umbilical vein endothelial cells (HUVECs) were purchased from Clonetics (Walkersville, MD) and cultured under an air:CO2 (19:1) atmosphere. HUVEC were grown in Endothelial Cell Growth Medium BulletKit (EGM-2) supplemented with 2\% (v/v) fetal bovine serum (FBS), hEGF, hydrocortisone, VEGF, hFGF-B, Long R3IGF-1, ascorbic acid, heparin, gentamicin and amphotericin-B. HUVEC were used up to the sixth passage. 


\section{In vitro fibrinolysis assay}

HUVECs were embedded within fibrin gels at a concentration of $1.2 \times 10^{6}$ cells $/ \mathrm{ml}$. Cells were centrifuged gently at $1000 \mathrm{rpm}$ for $3 \mathrm{~min}$ in $14 \mathrm{ml}$ tubes and the cell pellet resuspended in a mixture of $2.5 \mathrm{mg} / \mathrm{ml}$ plasminogen-free human fibrinogen and ${ }^{125} \mathrm{I}$ radiolabeled human fibrinogen $(0.15 \mu \mathrm{Ci} / \mathrm{ml})$ (made in serum-free medium). Thrombin $(0.5 \mathrm{U} / \mathrm{ml})$ was then added to the fibrinogen mixture, quickly pipetted into the wells of a 24-well plate ( $300 \mu \mathrm{l}$, covering the entire surface of the wells) and allowed to clot at $37^{\circ} \mathrm{C}$ for 30 min. After washing, EC medium containing $1 \%$ serum was added to the wells in the presence of angiogenic factors in order to induce fibrinolysis. For inhibition studies, protease inhibitors, PTK787, cycloheximide and antibodies were also added to the gels (prior to polymerization) and to the culture medium. Fibrin gels were incubated for several days at $37^{\circ} \mathrm{C}$ and $5 \% \mathrm{CO}_{2}(\mathrm{v} / \mathrm{v})$ and radiolabeled solubilized fibrin degradation products released in the media were quantified by $\gamma$ scintillation counting. The

spontaneous release of ${ }^{125}$ I-fibrin fragments from gels incubated in the presence of serumfree medium, which represented less than $5 \%$ of the measured signal, was used as a control. Fibrin gels were also incubated in the presence of DMSO to assess the effect of vehicle for BB94 and PTK787.

\section{Fibrinogen and plasminogen zymography assay}

Plasmin generation in the medium was detected by fibrinogen zymography. Culture media (40 $\mu$ l) or plasmin (positive control) were resolved under nonreducing conditions on $7.5 \%$ SDS-PAGE gels containing $1 \mathrm{mg} / \mathrm{ml}$ plasminogen-free fibrinogen. Gels were rinsed two times in $2.5 \%$ Triton X-100 for 30 min at room temperature to remove SDS, 
and the gels were further incubated at $37^{\circ} \mathrm{C}$ for $48 \mathrm{~h}$ in $20 \mathrm{mM} \mathrm{NaCl}, 5 \mathrm{mM} \mathrm{CaCl}$, 0.02\% Brij-35, $50 \mathrm{mM}$ Tris-HCl buffer, $\mathrm{pH}$ 7.6. Gels were stained with Coomassie Blue, and destained in 10\% (v/v) acetic acid/30\% methanol. Areas of fibrinogenolytic activity were visualized as transparent bands.

The activity of uPA and tPA secreted into the culture medium was assessed by casein/plasminogen zymography [24]. Briefly, conditioned media were separated by SDS-PAGE under nonreducing conditions on a 7.5\% acrylamide gel containing $1 \mathrm{mg} / \mathrm{ml}$ casein and $10 \mathrm{mg} / \mathrm{ml}$ human plasminogen. Electrophoresis was performed at $4^{\circ} \mathrm{C}$ and the resulting gels were washed twice for $30 \mathrm{~min}$ in $2.5 \%(\mathrm{v} / \mathrm{v})$ Triton $\mathrm{X}-100$ at room temperature and rinsed five times with nanopure water. Gels were incubated at $37^{\circ} \mathrm{C}$ in casein-plasminogen buffer (100 mM Tris-HCl, $\mathrm{pH} 8.0,50 \mathrm{mM}$ EDTA) for $3 \mathrm{~h}$. Plasminogen-dependent proteolysis was detected as a clear zone following staining with $0.1 \%(\mathrm{w} / \mathrm{v})$ Coomassie blue R-250 in $10 \%$ acetic acid/40\% methanol and destaining in $7.5 \%$ acetic acid $/ 30 \%$ methanol.

\section{RNA extraction and reverse transcription and polymerase chain reaction (RT-PCR)}

To isolate RNA from HUVEC within fibrin gels, cells were embedded as described above except that the fibrin solution was quickly pipetted into the wells of a 12-well plate $(570 \mu \mathrm{l})$ and allowed to clot at $37^{\circ} \mathrm{C}$ for $30 \mathrm{~min}$. After washing, serum-containing EC medium was added to the wells. The cells were incubated for $18 \mathrm{~h}$ at $37^{\circ} \mathrm{C}$ and $5 \% \mathrm{CO}_{2}$ $(\mathrm{v} / \mathrm{v})$. VEGF was then added for $4 \mathrm{~h}$ and total RNA was isolated by solubilizing the gels

with the TRIzol Reagent, according to the instructions of the manufacturer. RNA was 
dissolved in DEPC-treated water and quantitated at $260 \mathrm{~nm} .200 \mathrm{ng}$ of total RNA isolated from cells was amplified with the Superscript ${ }^{\mathrm{TM}}$ One-Step RT-PCR with Platinium ${ }^{\circledR}$ Taq reagent, using specifics primers and optimal annealing conditions that were determined in preliminary experiments (Table 1). Products were analyzed using $1.5 \%$ agarose gels containing ethidium bromide. 


\section{RESULTS}

\section{VEGF increases the fibrinolytic activity of endothelial cells embedded within a fibrin gel.}

In order to study the fibrinolytic activity of EC, we used a three dimensional cell culture model in which HUVEC were embedded in a radiolabeled fibrin gel, allowing a rapid and sensitive monitoring of fibrinolytic activity by liquid scintillation counting of fibrin fragments released in the cell culture medium.

We first used this model to evaluate the effect of various angiogenic factors on fibrin degradation by EC. As shown in Fig. 1A, serum alone had no effect on fibrinolysis but we observed that the addition of VEGF to the cell culture medium promoted a marked increase in the release of labeled fibrin fragments. This stimulatory effect was also observed for $\mathrm{HGF} / \mathrm{SF}$, albeit to a lower extent, while EGF, PDGF, bFGF or the lysophospholipids S1P and LPA had negligeable activities. The VEGF-dependent fibrinolytic activity of HUVECs was observed at concentrations as low as $25 \mathrm{ng} / \mathrm{mL}$, reaching a maximum at $50 \mathrm{ng} / \mathrm{mL}$ (Fig. 1B).

VEGF-induced fibrinolytic activity of endothelial cells within a fibrin gel involves VEGFR-2.

At the endothelial cell surface, VEGF binds to two receptors, VEGFR-1 and VEGFR-

2, the latter being responsible for the majority of the biological responses associated with VEGF [25]. To determine the involvement of this receptor, we first examined the effect 
of placental growth factor (PIGF), a member of the vascular endothelial growth factor family that interacts with VEGFR-1 but not with VEGFR-2 [26], on fibrinolysis. As shown in Fig. 2A, PIGF induced a minimal increase in the fibrinolytic activity of HUVECs, much less than that observed following stimulation with VEGF, suggesting the preferential involvement of VEGFR-2 in this process.

In order to confirm these results, we next investigated the effect of PTK787, a specific VEGFR tyrosine kinase inhibitor which possess a stronger inhibitory activity against VEGFR-2 [27]. As shown in figure 2B, PTK787 completely inhibited VEGFdependent fibrinolysis, with an $\mathrm{IC}_{50}$ of approximatively $40 \mathrm{nM}$, similar to the reported $\mathrm{IC}_{50}$ of this inhibitor for the tyrosine kinase activity of VEGFR-2 [27]. Overall, these results strongly suggest that the observed VEGF-dependent fibrinolytic activity of HUVEC is mediated by the VEGFR-2-dependent signaling cascade.

\section{VEGF-induced fibrinolytic activity of endothelial cells and generation of active plasmin in the culture medium are both plasminogen activator- and metalloprotease-dependent.}

We next investigated the involvement of the plasminogen activator/plasmin and MMP proteolytic systems in the VEGF-dependent proteolysis of fibrin matrices. As shown in Fig. 3A, the metalloprotease inhibitors BB94 and TIMP-2 completely inhibited the release of fibrin fragments in the culture medium. Interestingly, a similar inhibitory effect was also observed following treatment of the EC with type-1 plasminogen activator inhibitor (PAI-1) and aprotinin, two inhibitors of the plasminogen activator/plasmin axis. 
These results thus suggest that under the experimental conditions used in our study, the VEGF-dependent fibrin degradation by HUVEC is dependent on both plasmin and MMP activity.

Since a previous study has reported that tubulogenesis by EC embedded in a three dimensional fibrin matrix does not involve plasmin activity [19], we next determined whether the observed requirement for plasmin was related to an increased secretion of plasminogen activators by EC stimulated with VEGF. Cells were treated with VEGF in the absence or in the presence of inhibitors of the MMP or plasminogen activator/plasmin systems and the secretion of plasminogen activators and production of plasmin were monitored by plasminogen and fibrinogen zymography, respectively. As shown in Fig. 3B, VEGF induced an approximatively 2-fold increase in the secretion of tPA by HUVEC while that of uPA was much less modulated by the growth factor. As expected, the inhibition of VEGFR-2 activity using PTK787 completely abolished the release of tPA in the medium and reduced that of uPA, again emphasizing the important role of the VEGF signaling pathway in fibrinolysis. The addition of the physiological inhibitor tPA and $\mathrm{UPA}$ inhibitor PAI-1 also markedly decreased the secretion of tPA and UPA. By contrast, the inhibition of MMP activities by BB-94 as well as by TIMP-2 (data not shown) had no effect on the VEGF-induced release of tPA.

Fibrinogen zymography analysis confirmed that the increased secretion of tPA leads to the generation of plasmin in the culture medium. As shown in Fig. 3C, the addition of VEGF led to the time-dependent appeareance of plasmin activity in the medium, this increase being completely inhibited by PTK787 and PAI-1. Interestingly, we observed that in spite of its lack of inhibitory effect on the release of tPA, BB-94 nevertheless 
completely inhibited plasmin generation, suggesting that the observed inhibitory effect of this inhibitor on fibrinolysis may be related to its interference with the plasminogen activator-dependent conversion of plasminogen to plasmin.

\section{VEGF-induced fibrinolytic activity of endothelial cells correlates with increased mRNA for TPA and MT2-MMP.}

The VEGF-dependent increase in fibrinolysis was found to be highly sensitive to cycloheximide, a protein synthesis inhibitor, suggesting that it involves de novo synthesis of components of the fibrinolytic proteolytic pathway (Fig. 4A). To preliminary characterize the proteins involved, we isolated total RNA from HUVEC embedded in the fibrin matrix and monitored the variation in mRNA levels of tPA, uPA and of membrane-type MMPs following a $4 \mathrm{~h}$ stimulation of the cells with VEGF. As shown in Fig. 4B, VEGF induced a marked increase in the mRNA levels of tPA while those of uPA were not significantly modulated by the treatment. Interestingly, the inhibitory profile of inhibitors on mRNA levels parallels that previously observed for the inhibition of the secretion of plasminogen activators by HUVEC (Fig. 3B) since PTK787 and PAI1, but not BB-94, completely inhibited the VEGF-dependent induction of tPA mRNA levels (Fig. 4B). These results thus strongly suggest that tPA is the predominant PA involved in the VEGF-dependent fibrinolytic activity of HUVEC in a three dimensional fibrin matrix, an hypothesis strongly supported by the complete inhibition of release of fibrin fragments by a function-blocking monoclonal antibody that specifically recognize the enzyme (Fig. 4C). 
Based on the reported involvement of membrane-type MMPs in EC tubulogenesis, we also monitored the effect of VEGF on the mRNA levels of MT1-, MT2- and MT3MMP. As shown in Fig. 4B, MT2-MMP mRNA levels were strongly increased by VEGF, this increase being completely abolished by the VEGFR inhibitor but not by MMP or PA inhibitors. By contrast, MT1- and MT3-MMP mRNA levels remained largely unaffected by VEGF, raising the possibility that MT2-MMP may participate to the VEGF-dependent increase in fibrinolysis. 


\section{DISCUSSION}

Fibrin matrices play essential roles in the initiation and propagation of angiogenic responses by serving as a provisional matrix that sustains the formation of neovessels [28]. However, the dense cross-linked structure of fibrin also represents a major obstacle for endothelial cell locomotion and EC rely on the fibrinolytic activities of the plasminogen activator/plasmin and MMP proteolytic systems to invade fibrin networks [8]. The interrelationship between these systems appears complex since fibrinolysis was found to be critically dependent on either uPA/plasmin activity [11, 12], MMP activities $[17,19]$ or on both classes of proteases $[20,29]$. It is thus likely that the reliance on MMP- versus plasmin-dependent fibrin degradation may depend on the microenvironment surrounding the blood vessels, especially the biochemical nature of the angiogenic stimuli [17].

In order to study the factors involved in the control of EC-mediated fibrinolysis, we used a model in which EC are embedded in a three dimensional fibrin matrix in the presence of plasminogen from the culture medium. Under these conditions, we observed that fibrinolysis was critically dependent on the presence of VEGF and involves both the PA/plasminogen and MMP proteolytic systems. We observed that stimulation of EC with VEGF induced an increase in the tPA levels but not those of uPA, in agreement with previous studies showing that VEGF is a much more potent inducer of t-PA than of uPA in bovine microvascular endothelial cells, at both the mRNA and protein levels [30, 31$]$.

This increase in the levels of tPA seems crucial in terms of fibrinolysis since a function- 
blocking monoclonal antibody that specifically recognizes this enzyme completely inhibited fibrin degradation.

In addition to the important role of tPA-mediated plasmin formation for the VEGFinduced fibrin degradation by HUVEC, we also observed that this process was highly dependent on MMP activity. Fibrinolysis was completely abolished by BB-94, a broad spectrum inhibitor of MMP as well as by the addition of low concentrations of TIMP-2, a physiological MMP inhibitor. This inhibitory effect of MMP inhibitors is not related to an interference with the VEGF-dependent increase in the tPA mRNA levels nor on its release in the culture medium but rather with the formation of plasmin in the culture medium. This strongly suggests the involvement of the MMP activity in the tPAdependent conversion of plasminogen to plasmin. In this respect, it is noteworthy that a recent report has documented the MMP-dependent activation of pro-uPA to active uPA following VEGF stimulation of HUVEC, this process involving a rapid and posttranslational (cycloheximide-insensitive) PI3-kinase-dependent activation of integrinassociated proMMP-2 [29]. Such a mechanism is however unlikely to play a significant role under our experimental conditions since we observed that fibrinolysis rather involved tPA, was sensitive to cycloheximide and was not associated with the activation of proMMP-2 in the culture medium (data not shown). Although the mechanisms responsible for the participation of a MMP activity in the formation of plasmin remain to be established, the upregulation of some membrane-type MMPs endowed with fibrinolytic properties, such as MT2-MMP, may suggest that fibrinolysis mediated by 
these MMPs could generate binding sites for plasminogen to fibrin, leading to enhanced plasmin production and fibrinolysis [32].

The requirement for tPA in EC-mediated fibrinolysis was unexpected since uPA was previously shown to play essential roles in the invasion of fibrin matrices by EC of human origin $[11,12]$ and is generally considered the most prominent PA involved in EC invasive properties [33]. Although the role of tPA in angiogenesis remains much less understood, it has been suggested that its release from Weibel-Palade bodies may prevent fibrin deposition in coagulation-prone neovessels $[8,33]$. In support to this hypothesis, the VEGF-dependent induction of tPA in bovine microvascular cells resulted in the localization of the enzyme in Weibel-Palade bodies [34] and VEGF was recently shown to activate Weibel-Palade bodies exocytosis [35]. However, the involvement of this pathway in the tPA-dependent fibrinolysis observed in our study is unlikely since VEGFinduced exocytosis occurs within 5 minutes of stimulation, in agreement with its role in the immediate response of EC to injury, independent of gene transcription [36]. S1P, another activator of Weibel-Palade body exocytosis [37] had no stimulatory effect on fibrinolysis, further suggesting that this process is not involved in the observed degradation of fibrin.

In summary, our results suggest that endothelial cells embedded in a three dimensional fibrin matrix express a complex proteolytic repertoire upon stimulation with VEGF, of which tPA is a prominent regulator of pericellular fibrinolysis. Since plasmin(ogen)-enhanced invasion by endothelial cells is blocked by both angiostatin and anti-catalytic t-PA antibodies [38], it is tempting to speculate that the observed increased 
of tPA activity plays an important role in angiogenesis. Further studies on the mechanisms governing the control of tPA-dependent production of plasmin by MMP activity is underway and should provide interesting new insights on the cooperation between PA and MMP in angiogenesis. 


\begin{tabular}{|l|l|l|}
\hline \multicolumn{1}{|c|}{ Target } & \multicolumn{2}{|c|}{ Amplification parameters (40 cycles) } \\
\hline \multirow{2}{*}{ tPA } & \multicolumn{1}{|c|}{ Sequences of primers } & \multicolumn{1}{|c|}{$\begin{array}{c}\text { Annealing } \\
\text { conditions }\end{array}$} \\
\hline uPA & $\begin{array}{l}\text { Sense: 5'-CTGCAGCTGAAATCGGATTC-3' } \\
\text { Reverse: 5'-CTGATGATGCCCACCAAAGT -3' }\end{array}$ & $60^{\circ} \mathrm{C}, 30 \mathrm{~s}$ \\
\hline MT1-MMP & $\begin{array}{l}\text { Sense: 5'-GGCAGCAATGAAGTTCATAA-3' } \\
\text { Reverse : 5'-TATCTCACAGTGTTCCCCTT-3' }\end{array}$ & $\begin{array}{l}\text { Sense: 5'-CAACACTGCCTACGAGAGGA-3' } \\
\text { Reverse : 5'-GTTCTACCTTCAGCTTCTGG-3' }\end{array}$ \\
\hline MT2-MMP & $\begin{array}{l}\text { Sense: 5'-GCATCCAGAACTACACGGAG-3' } \\
\text { Reverse : 5'-TAACGTAGAGCTGCTGGATG-3' }\end{array}$ & $60^{\circ} \mathrm{C}, 30 \mathrm{~s}$ \\
\hline MT3-MMP & $\begin{array}{l}\text { Sense: 5'-TGTACCTGACCAGACAAGAG-3' } \\
\text { Reverse : 5'-AGT-GTCCATGGCTCATCTGA3' }\end{array}$ & $52^{\circ} \mathrm{C}, 60 \mathrm{~s}$ \\
\hline$\beta$-actin & $\begin{array}{l}\text { Sense: 5'CACCTTCTACAATGAGCTGC-3' } \\
\text { Reverse: 5'AGGCAAGCTCGTAGCTCTTCT-3' }\end{array}$ & $50^{\circ} \mathrm{C}, 45 \mathrm{~s}$ \\
\hline
\end{tabular}

Table 1. Primers and annealing conditions used in RT-PCR experiments. 


\section{LEGENDS TO FIGURES}

Figure 1. VEGF increases the fibrinolytic activity of endothelial cells within fibrin gels (A) HUVECs were grown within fibrin gels in standard serum-containing medium and stimulated with the indicated angiogenic factors : VEGF $(50 \mathrm{ng} / \mathrm{ml})$, HGF/SF (40 ng/ml), EGF (50 ng/ml), PDGF-BB (50 ng/ml), bFGF (20 ng/ml), S1P (1 $\mu \mathrm{M})$, LPA $(10 \mu \mathrm{M})$. The cells were incubated at $37^{\circ} \mathrm{C}$ and $5 \% \mathrm{CO}_{2}(\mathrm{v} / \mathrm{v})$ for $48 \mathrm{~h}$ and solubilized radiolabeled fibrin degradation products contained in the media were quantified by $\gamma$-scintillation counting. (B) HUVECs were grown within fibrin gels in standard serum-containing medium and stimulated with increasing concentrations of VEGF. The cells were incubated at $37^{\circ} \mathrm{C}$ and $5 \% \mathrm{CO}_{2}(\mathrm{v} / \mathrm{v})$ for $65 \mathrm{~h}$ and the extent of fibrinolysis monitored as described above. After removing the media, the cells and fibrin gels were fixed and stained with $0.1 \%$ crystal violet $/ 20 \% \mathrm{MeOH}$.

\section{Figure 2. Involvement of VEGFR-2 in the VEGF-induced fibrinolytic activity} of endothelial cells. (A) HUVECs were grown within fibrin gels in standard serumcontaining medium and stimulated with increasing concentrations of VEGF or PIGF $(0.1$ to $1 \mathrm{nM})$. The cells were incubated at $37^{\circ} \mathrm{C}$ and $5 \% \mathrm{CO}_{2}(\mathrm{v} / \mathrm{v})$ for $48 \mathrm{~h}$ and solubilized radiolabeled fibrin degradation products contained in the media were quantified by $\gamma$ scintillation counting. (B) HUVECs were grown within fibrin gels containing PTK787 $(50 \mathrm{nM}$ to $1 \mu \mathrm{M})$ for $3 \mathrm{~h}$ in standard serum-containing medium and then VEGF ( $1 \mathrm{nM}$ final concentration) and/or PTK787 were added to the medium. The cells were incubated at $37^{\circ} \mathrm{C}$ and $5 \% \mathrm{CO}_{2}(\mathrm{v} / \mathrm{v})$ for $48 \mathrm{~h}$ and the extent of fibrinolysis monitored as described above. 


\section{Fig. 3. Effect of protease inhibitors on the VEGF-induced fibrinolytic}

activity of endothelial cells within fibrin gels (A) HUVECs were grown within fibrin gels in standard serum-containing medium and stimulated with VEGF (1 nM final concentration). Protease inhibitors were added both to the gel and to the culture medium at the beginning of the experiment. The cells were incubated at $37^{\circ} \mathrm{C}$ and $5 \% \mathrm{CO}_{2}(\mathrm{v} / \mathrm{v})$ for $65 \mathrm{~h}$ and solubilized radiolabeled fibrin degradation products contained in the media were quantified by $\gamma$-scintillation counting. (B) Plasminogen-casein and fibrinogen (C) zymography of culture media were performed as described in "Materials and Methods", using commercial preparations of tPA, uPA and plasmin as standrads.

Fig. 4. Involvement of tPA in VEGF-induced fibrinolysis. (A) HUVECs were grown within fibrin gels in standard serum-containing medium and stimulated with VEGF (1 nM final concentration) in the absence or in the presence of cycloheximide (10 $\mu \mathrm{M}$ ). (B) HUVECs were cultured within fibrin gels in standard serum-containing medium for $18 \mathrm{~h}$ and then stimulated with VEGF for $4 \mathrm{~h}$. Total RNA was extracted from the cells and RT-PCR was performed using primers specific for the indicated proteins. (C) HUVECs were grown within fibrin gels in standard serum-containing medium and stimulated with VEGF in the presence of a function-blocking monoclonal antibody against tPA or an unrelated IgG1 antibody as a control. 
Figure 1

A

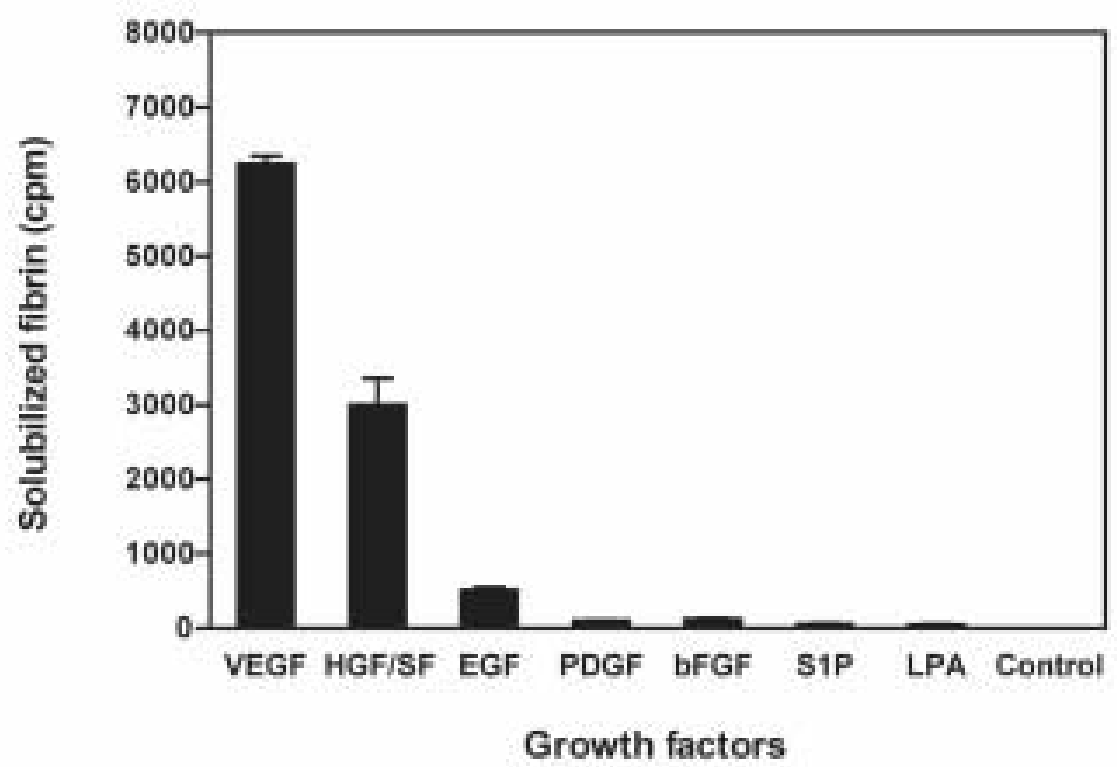

B

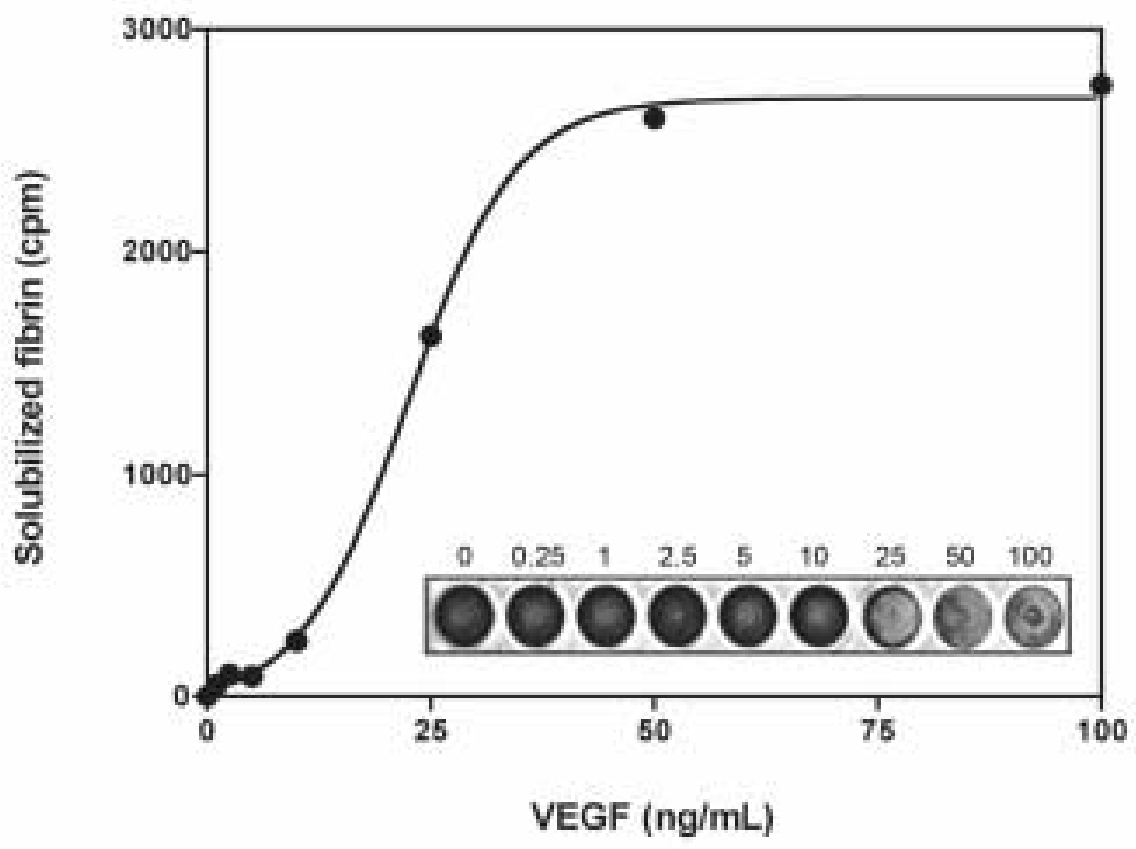


Figure 2

A

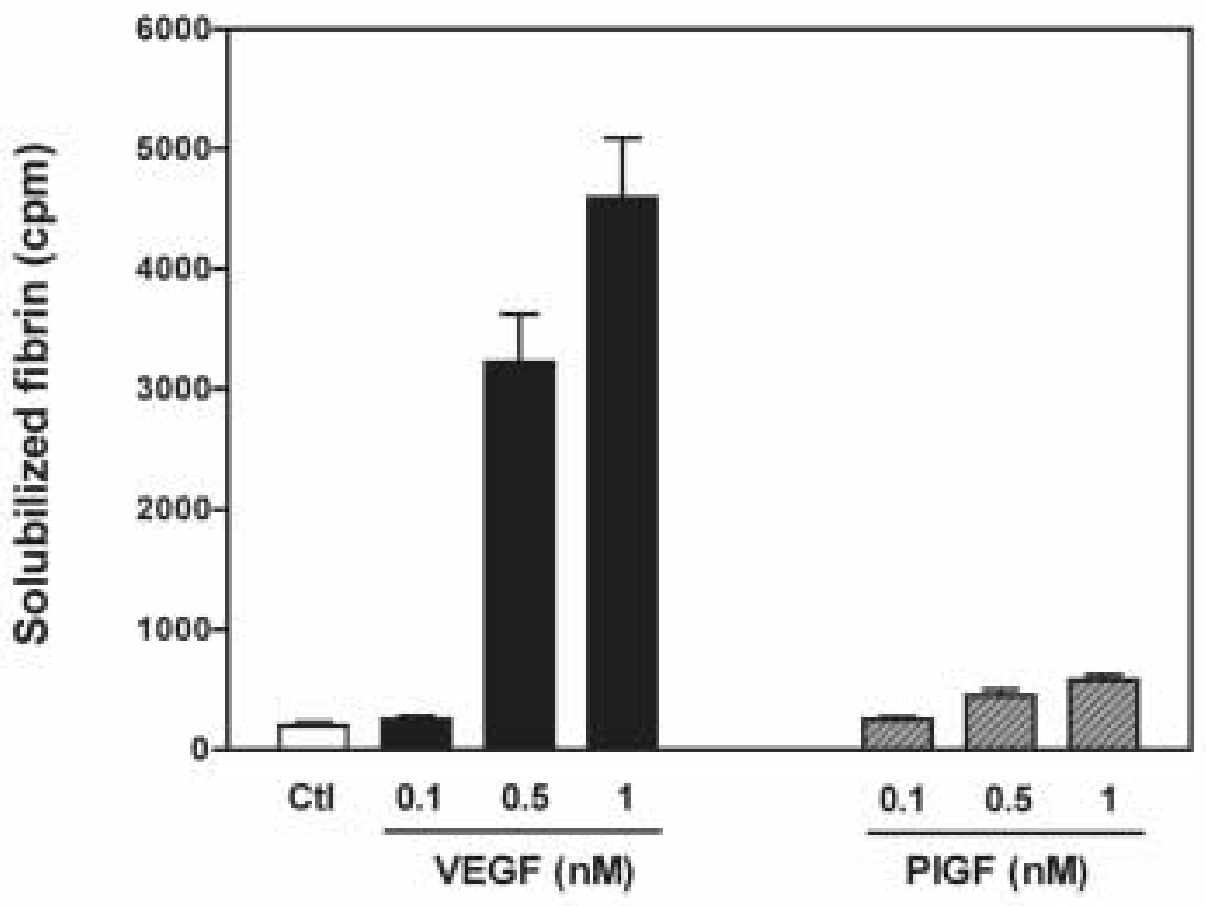

Figure 2 (cont'd) 
B

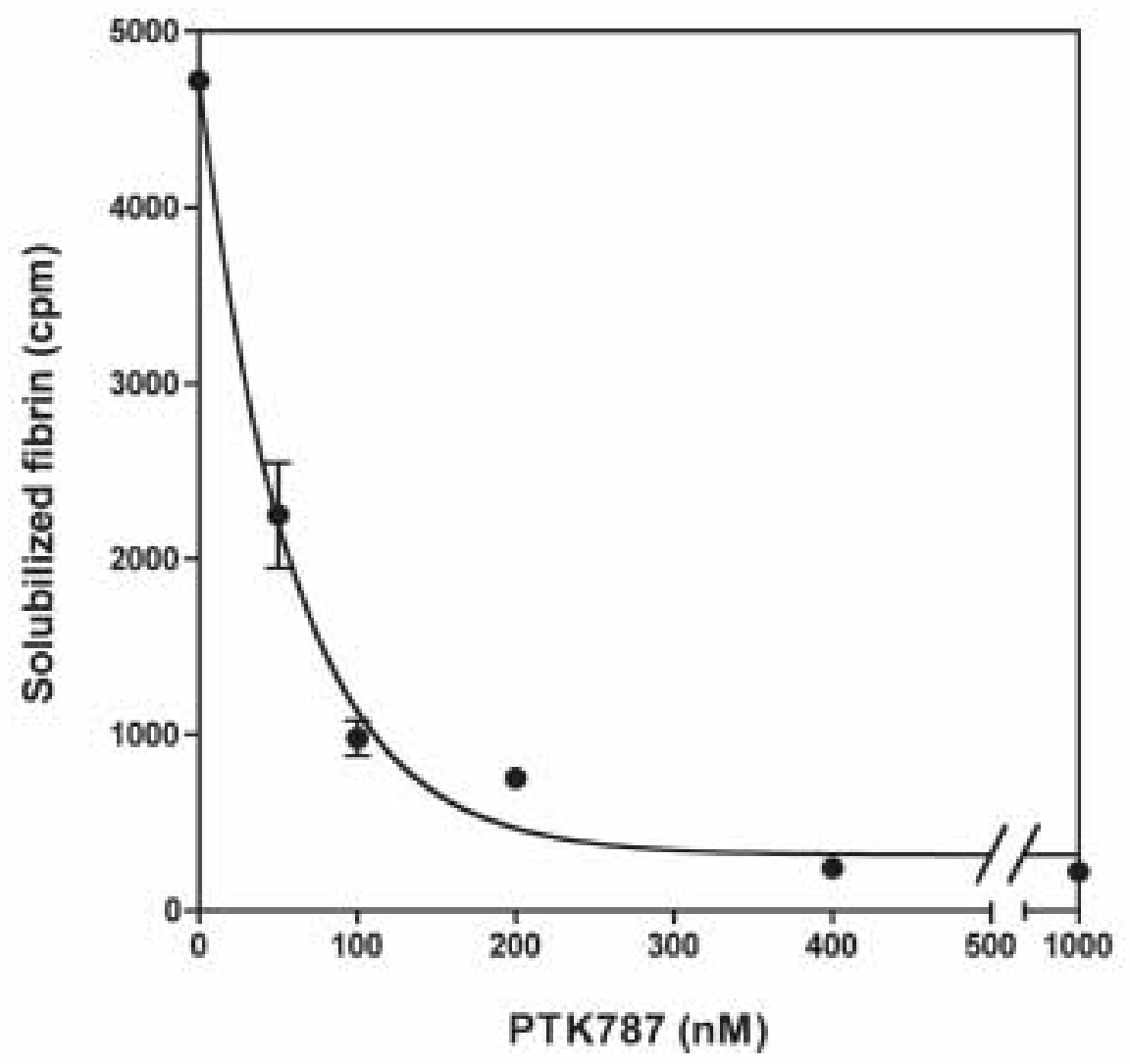




\section{Figure 3}

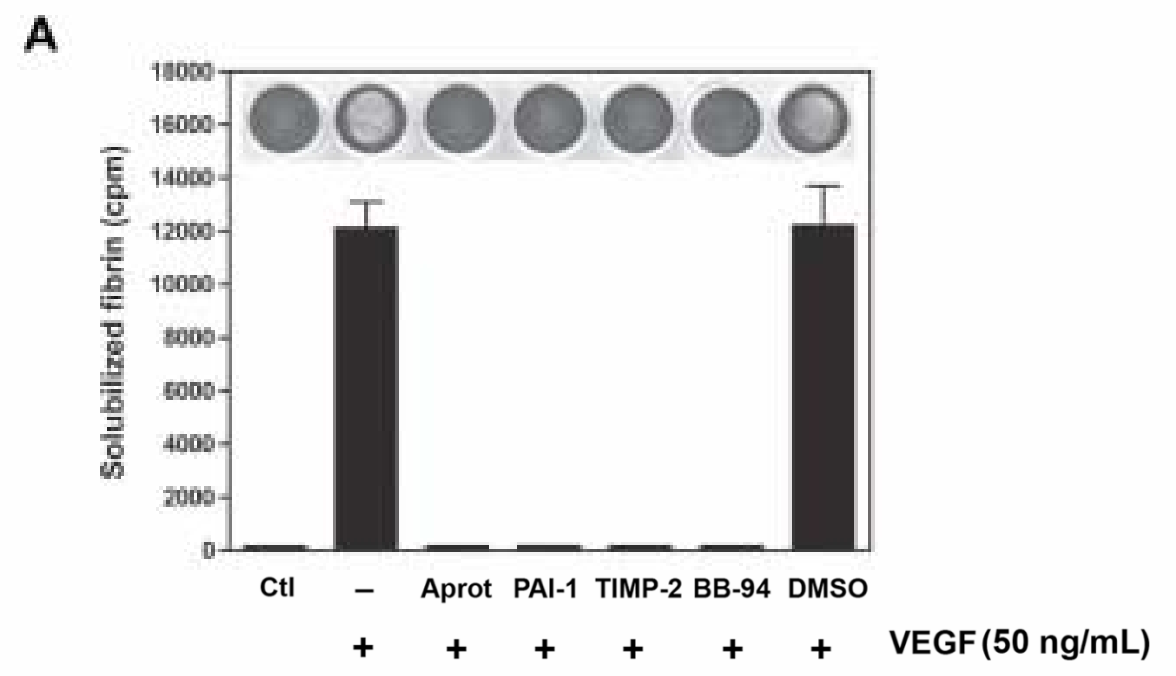

B

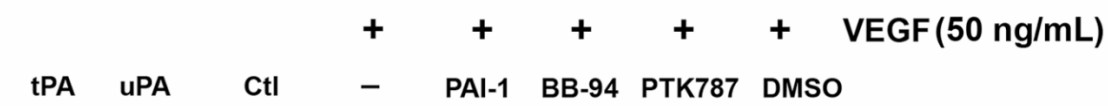

C
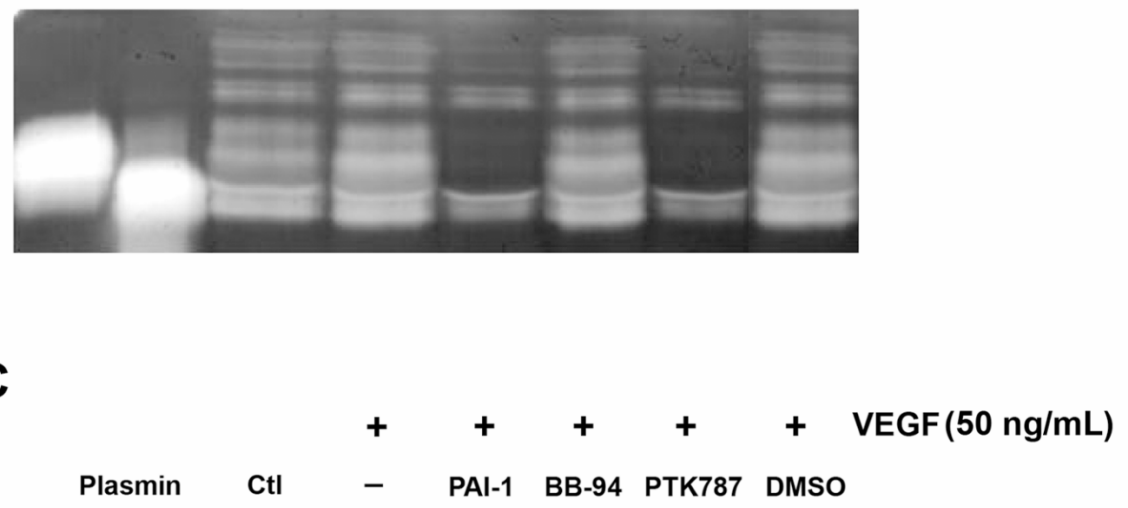

$1 \mathrm{~h}$

$4 \mathrm{~h}$

$8 \mathrm{~h}$

$24 \mathrm{~h}$ 
Figure 4

A

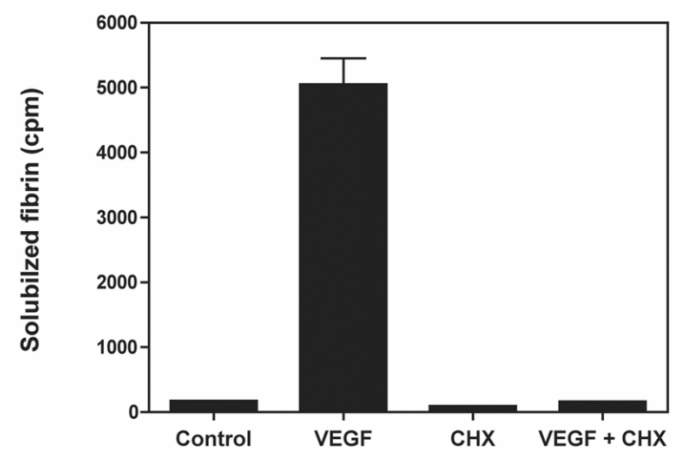

B
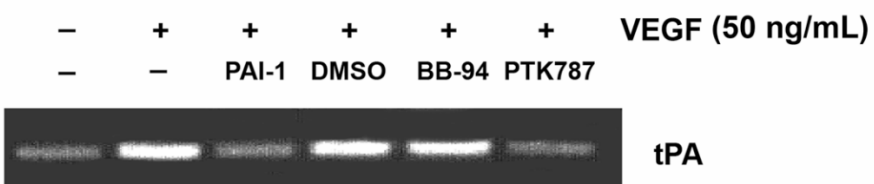

tPA

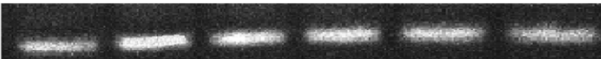

uPA

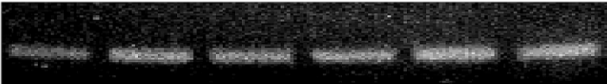

MT1-MMP

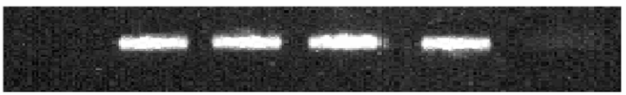

MT2-MMP

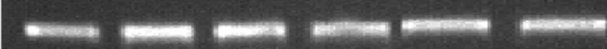

MT3-MMP

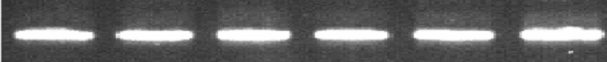

$\beta$-actin

C

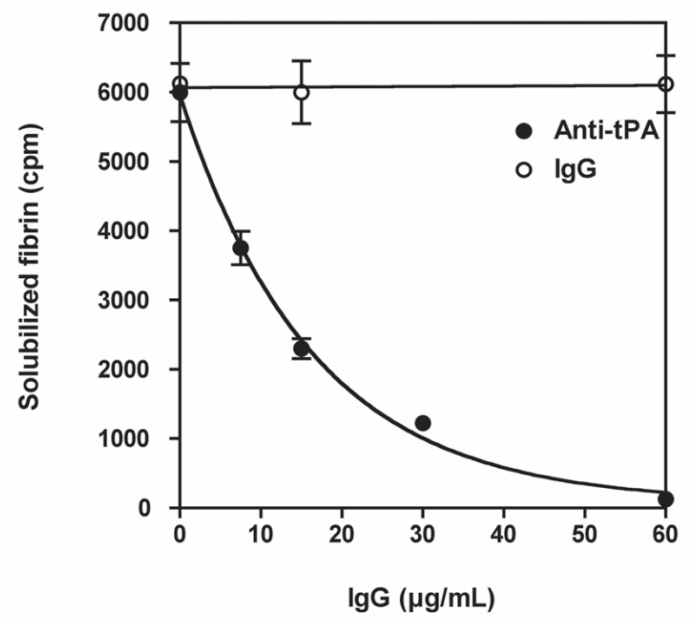




\section{REFERENCES}

[1] N. Ferrara, and H. P. Gerber, The role of vascular endothelial growth factor in angiogenesis, Acta Haematol 106 (2001) 148-156.

[2] T. Matsumoto, and L. Claesson-Welsh, VEGF receptor signal transduction, Sci STKE 2001 (2001) RE21.

[3] H. F. Dvorak, L. F. Brown, M. Detmar, and A. M. Dvorak, Vascular permeability factor/vascular endothelial growth factor, microvascular hyperpermeability, and angiogenesis, Am J Pathol 146 (1995) 1029-1039.

[4] B. Vailhe, X. Ronot, P. Tracqui, Y. Usson, and L. Tranqui, In vitro angiogenesis is modulated by the mechanical properties of fibrin gels and is related to alpha(v)beta3 integrin localization, In Vitro Cell Dev Biol Anim 33 (1997) 763-773.

[5] G. F. Nash, D. C. Walsh, and A. K. Kakkar, The role of the coagulation system in tumour angiogenesis, Lancet Oncol 2 (2001) 608-613.

[6] M. Z. Wojtukiewicz, E. Sierko, P. Klement, and J. Rak, The hemostatic system and angiogenesis in malignancy, Neoplasia 3 (2001) 371-384.

[7] F. R. Rickles, and A. Falanga, Molecular basis for the relationship between thrombosis and cancer, Thromb Res 102 (2001) V215-224.

[8] M. S. Pepper, Role of the matrix metalloproteinase and plasminogen activatorplasmin systems in angiogenesis, Arterioscler Thromb Vasc Biol 21 (2001) 1104-1117.

[9] D. Collen, and H. R. Lijnen, Basic and clinical aspects of fibrinolysis and thrombolysis, Blood 78 (1991) 3114-3124.

[10] P. A. Andreasen, R. Egelund, and H. H. Petersen, The plasminogen activation system in tumor growth, invasion, and metastasis, Cell Mol Life Sci 57 (2000) 25-40.

[11] P. Koolwijk, M. G. van Erck, W. J. de Vree, M. A. Vermeer, H. A. Weich, R. Hanemaaijer, and V. W. van Hinsbergh, Cooperative effect of TNFalpha, bFGF, and VEGF on the formation of tubular structures of human microvascular endothelial cells in a fibrin matrix. Role of urokinase activity, J Cell Biol 132 (1996) 1177-1188. 
[12] M. E. Kroon, P. Koolwijk, H. van Goor, U. H. Weidle, A. Collen, G. van der Pluijm, and V. W. van Hinsbergh, Role and localization of urokinase receptor in the formation of new microvascular structures in fibrin matrices, Am J Pathol 154 (1999) 1731-1742.

[13] K. Mimura, K. Sueishi, C. Yasunaga, and K. Tanaka, Fibrinolysis activity promotes tumor invasiveness of B16 melanoma cell lines through a reconstituted gel matrix, Invasion Metastasis 12 (1992) 24-34.

[14] Y. Sugiura, L. Ma, B. Sun, H. Shimada, W. E. Laug, R. C. Seeger, and Y. A. DeClerck, The plasminogen-plasminogen activator (PA) system in neuroblastoma: role of PA inhibitor-1 in metastasis, Cancer Res 59 (1999) 1327-1336.

[15] V. M. Diaz, J. Planaguma, T. M. Thomson, J. Reventos, and R. Paciucci, Tissue plasminogen activator is required for the growth, invasion, and angiogenesis of pancreatic tumor cells, Gastroenterology 122 (2002) 806-819.

[16] P. Carmeliet, A. Bouche, C. De Clercq, S. Janssen, S. Pollefeyt, S. Wyns, R. C. Mulligan, and D. Collen, Biological effects of disruption of the tissue-type plasminogen activator, urokinase-type plasminogen activator, and plasminogen activator inhibitor-1 genes in mice, Ann N Y Acad Sci 748 (1995) 367-381; discussion 381-362.

[17] N. Hiraoka, E. Allen, I. J. Apel, M. R. Gyetko, and S. J. Weiss, Matrix metalloproteinases regulate neovascularization by acting as pericellular fibrinolysins, Cell 95 (1998) 365-377.

[18] K. B. Hotary, I. Yana, F. Sabeh, X. Y. Li, K. Holmbeck, H. Birkedal-Hansen, E. D. Allen, N. Hiraoka, and S. J. Weiss, Matrix metalloproteinases (MMPs) regulate fibrininvasive activity via MT1-MMP-dependent and -independent processes, J Exp Med 195 (2002) 295-308.

[19] M. A. Lafleur, M. M. Handsley, V. Knauper, G. Murphy, and D. R. Edwards, Endothelial tubulogenesis within fibrin gels specifically requires the activity of membrane-type-matrix metalloproteinases (MT-MMPs), J Cell Sci 115 (2002) 34273438. 
[20] A. Collen, R. Hanemaaijer, F. Lupu, P. H. Quax, N. van Lent, J. Grimbergen, E. Peters, P. Koolwijk, and V. W. van Hinsbergh, Membrane-type matrix metalloproteinasemediated angiogenesis in a fibrin-collagen matrix, Blood 101 (2003) 1810-1817.

[21] J. A. Pedersen, and M. A. Swartz, Mechanobiology in the third dimension, Ann Biomed Eng 33 (2005) 1469-1490.

[22] M. Schindler, E. K. A. Nur, I. Ahmed, J. Kamal, H. Y. Liu, N. Amor, A. S. Ponery, D. P. Crockett, T. H. Grafe, H. Y. Chung, T. Weik, E. Jones, and S. Meiners, Living in three dimensions: 3D nanostructured environments for cell culture and regenerative medicine, Cell Biochem Biophys 45 (2006) 215-227.

[23] L. Labrecque, C. Nyalendo, S. Langlois, Y. Durocher, C. Roghi, G. Murphy, D. Gingras, and R. Beliveau, Src-mediated Tyrosine Phosphorylation of Caveolin-1 Induces Its Association with Membrane Type 1 Matrix Metalloproteinase, J. Biol. Chem. 279 (2004) 52132-52140.

[24] D. Gingras, C. Nyalendo, G. Di Tomasso, B. Annabi, and R. Beliveau, Activation of tissue plasminogen activator gene transcription by Neovastat, a multifunctional antiangiogenic agent, Biochem Biophys Res Commun 320 (2004) 205-212.

[25] M. Shibuya, Vascular endothelial growth factor (VEGF)-Receptor2: its biological functions, major signaling pathway, and specific ligand VEGF-E, Endothelium 13 (2006) 63-69.

[26] S. De Falco, B. Gigante, and M. G. Persico, Structure and function of placental growth factor, Trends Cardiovasc Med 12 (2002) 241-246.

[27] J. M. Wood, G. Bold, E. Buchdunger, R. Cozens, S. Ferrari, J. Frei, F. Hofmann, J. Mestan, H. Mett, T. O'Reilly, E. Persohn, J. Rosel, C. Schnell, D. Stover, A. Theuer, H. Towbin, F. Wenger, K. Woods-Cook, A. Menrad, G. Siemeister, M. Schirner, K. H. Thierauch, M. R. Schneider, J. Drevs, G. Martiny-Baron, and F. Totzke, PTK787/ZK 222584, a novel and potent inhibitor of vascular endothelial growth factor receptor tyrosine kinases, impairs vascular endothelial growth factor-induced responses and tumor growth after oral administration, Cancer Res 60 (2000) 2178-2189. 
[28] H. F. Dvorak, D. R. Senger, and A. M. Dvorak, Fibrin as a component of the tumor stroma: origins and biological significance, Cancer Metastasis Rev 2 (1983) 41-73.

[29] G. W. Prager, J. M. Breuss, S. Steurer, J. Mihaly, and B. R. Binder, Vascular endothelial growth factor (VEGF) induces rapid prourokinase (pro-uPA) activation on the surface of endothelial cells, Blood 103 (2004) 955-962.

[30] M. S. Pepper, N. Ferrara, L. Orci, and R. Montesano, Vascular endothelial growth factor (VEGF) induces plasminogen activators and plasminogen activator inhibitor-1 in microvascular endothelial cells, Biochemical and Biophysical Research Communications 181 (1991) 902.

[31] R. Buser, R. Montesano, I. Garcia, P. Dupraz, and M. S. Pepper, Bovine microvascular endothelial cells immortalized with human telomerase, J Cell Biochem 98 (2006) 267-286.

[32] D. C. Rijken, and D. V. Sakharov, Basic principles in thrombolysis: regulatory role of plasminogen, Thromb Res 103 Suppl 1 (2001) S41-49.

[33] M. A. Engelse, R. Hanemaaijer, P. Koolwijk, and V. W. van Hinsbergh, The fibrinolytic system and matrix metalloproteinases in angiogenesis and tumor progression, Semin Thromb Hemost 30 (2004) 71-82.

[34] M. S. Pepper, C. Rosnoblet, C. Di Sanza, and E. K. Kruithof, Synergistic induction of t-PA by vascular endothelial growth factor and basic fibroblast growth factor and localization of t-PA to Weibel-Palade bodies in bovine microvascular endothelial cells, Thromb Haemost 86 (2001) 702-709.

[35] K. Matsushita, M. Yamakuchi, C. N. Morrell, M. Ozaki, B. O'Rourke, K. Irani, and C. J. Lowenstein, Vascular endothelial growth factor regulation of Weibel-Palade-body exocytosis, Blood 105 (2005) 207-214.

[36] C. J. Lowenstein, C. N. Morrell, and M. Yamakuchi, Regulation of Weibel-Palade Body Exocytosis, Trends in Cardiovascular Medicine 15 (2005) 302.

[37] K. Matsushita, C. N. Morrell, and C. J. Lowenstein, Sphingosine 1-phosphate activates Weibel-Palade body exocytosis, PNAS 101 (2004) 11483-11487. 
[38] M. S. Stack, S. Gately, L. M. Bafetti, J. J. Enghild, and G. A. Soff, Angiostatin inhibits endothelial and melanoma cellular invasion by blocking matrix-enhanced plasminogen activation, Biochem J 340 (Pt 1) (1999) 77-84. 